\title{
Thermal Runaway Conditions of a Partially Diluted Catalytic Reactor
}

\author{
Margarida M. J . Quina and Rosa M. Quinta Ferreira* \\ Department of Chemical Engineering, University of Coimbra, 3000 Coimbra, Portugal
}

The generalized parametric sensitivity criterion was used to obtain runaway diagrams for oneand two-dimensional heterogeneous models and a one-dimensional pseudo-homogeneous model. The simulation work was based on the partial methanol oxidation to formaldehyde, which occurs in a fixed-bed reactor, with two distinct catalytic zones. At the inlet of the reactor, the catalyst was diluted with inert packing followed by a region with pure catalyst. This activity profile induces a reduction in the parametric sensitivity of the process to temperature runaway, when compared to a uniform activity bed, and the sensitivity functions reach a minimum when the inlet temperature is in the range of $530-540 \mathrm{~K}$. The dilution of the catalytic bed leads to an enlargement of the stable region of operation, which allows a gain in the critical methanol concentration of $20 \%$ for a feed temperature of $530 \mathrm{~K}$ (industrial operating temperature), higher gains being possible ( $40 \%)$ for higher inlet temperatures. Moreover, depending on the particular set of the operating conditions, one or two hot spots can be developed, one in each zone of the bed, it being important to follow both because one or the other can determine the critical conditions of the system. The additional mass flux by intraparticle convection leads to an increase in the parametric sensitivity when compared with the case where diffusion is the only mechanism taken into account.

\section{Introduction}

When an exothermic reaction is considered in a nonadiabatic tubular reactor, the temperature profile can exhibit at least one maximum value, usually referred to as the hot spot. For certain values of the operating conditions, the magnitude of such hot spots can become quite sensitive to small variations of any inlet parameter of the system. This behavior was first analyzed in the area of chemical reactors by Bilous and Amundson ${ }^{1}$ who introduced the concept of parametric sensitivity, and since then it has been studied by several authors. Various a priori criteria have been devel oped to determine the regions of parametric sensitivity or temperature runaway in the reactor, so that they can be avoided in the earlier stages of the reactor design, and during the system operation. Most criteria were based on the geometry of the temperature profiles: Adler and Enig, ${ }^{2}$ Dente and Collina, ${ }^{3}$ van Welsenaere and Froment, ${ }^{4}$ and Morbidelli and Varma. ${ }^{5}$ However, M orbidelli and Varma ${ }^{6}$ have proposed a new generalized criterion for parametric sensitivity based on the sensitivity coefficient of the hot spot temperature to the model input parameters. This method has al ready been used on several types of systems: catalytic tubular reactors, ${ }^{7-12}$ cool ed reactors, ${ }^{13,14}$ continuous-stirred tank reactors, ${ }^{6}$ batch reactors, ${ }^{15}$ and thermal explosion theory. 6,16 Various works have been published in the literature deal ing with model predictions $\mathrm{s}^{13-22}$ and a few experimental studies have been carried out. ${ }^{23-27}$ The studies related to parametric sensitivity are generally based on simple reactions, but some authors consi dered compl ex reactions and refer to the influence of yield and

* To whom correspondence should be addressed. E-mail: eq1rqf@eq.uc.pt. Tel.: 351-(0)39-798700. selectivity on thermal runaway. 9,28,29 Most of the work developed before the 70s was carried out by using pseudo-homogeneous models. However, the studies presented by McGreavy and Adderley 30 revealed that the heterogeneity of the catalytic reactors must be considered in the analysis of the parametric sensitivity of a system. Morbidelli and Varma 7,8 al so concluded that heterogeneous models should be used to reproduce the experimental results obtained by E mig et al. ${ }^{24}$ Balakotaiah et al. ${ }^{12}$ and Balakotaiah and Luss ${ }^{31}$ emphasized the use of this type of models and presented simple criteria to calculate the parametric sensitive region. The two-dimensional models have been seldom used to study the parametric sensitivity. Baptista and Castro ${ }^{32}$ considered a two-dimensional model and have shown that there are some unstable operating conditions that are stated as stable by the one-dimensional model.

The main objectives of the present work are centered in the analysis of the region of parametric sensitivity and the range of operating conditions leading to the phenomenon of temperature runaway for a fixed-bed reactor where the catalytic bed is partially diluted with inert packing. The Generalized Parametric Sensitivity Criterion (GPSC) developed by Morbidelli and Varma ${ }^{6}$ based on the sensitivity coefficients of the hot spot temperature to the model input parameters was used.

\section{Mathematical Models}

The selective oxidation of methanol to formal dehyde over iron/molybdenum-oxides catalysts has been selected as the case studied, with operating conditions corresponding to the industrial ones. The main reaction in this system is the partial oxidation of methanol to formal dehyde, and a side reaction involving the oxidation of formaldehyde to carbon monoxide and water was 
Table 1. Dimensionless Equations for the One-Dimensional Heterogeneous Model, with Diffusion and Convection inside the Catalyst, HTID dc

\begin{tabular}{ll}
\hline mass balance & $\frac{\mathrm{df} f_{\mathrm{i}, \mathrm{b}}}{\mathrm{dz}}=\mathrm{Da} \sum_{\mathrm{j}=1}^{2} \alpha_{\mathrm{i}, \mathrm{j}} \mathrm{R}{ }_{\mathrm{j}}^{\mathrm{s}} \eta_{\mathrm{j}}$ \\
energy balance & $\frac{\mathrm{d} \theta_{\mathrm{b}}}{\mathrm{d} z^{*}}=\mathrm{Da} \sum_{\mathrm{j}=1}^{2} \mathrm{~B}_{\mathrm{j}} \mathrm{R}{ }_{\mathrm{j}}^{\mathrm{s}} \eta_{\mathrm{j}}+\mathrm{N}_{\mathrm{w}}\left(\theta_{\mathrm{w}}-\theta_{\mathrm{b}}\right)$ \\
initial conditions & $\mathrm{z}^{*}=0 ; \mathrm{f}_{\mathrm{i}, \mathrm{b}}=\mathrm{C}_{\mathrm{i}, \mathrm{o}} / \mathrm{C}_{\mathrm{M}, 0 ;} ; \theta_{\mathrm{b}=1}$ \\
mass balance & $-\mathrm{Nf}_{\mathrm{i}}\left(\mathrm{f}_{\mathrm{i}, \mathrm{b}}-\mathrm{f}_{\mathrm{i}, \mathrm{s}}\right)=\mathrm{Da} \sum_{\mathrm{j}=1}^{2} \alpha_{\mathrm{i}, \mathrm{j}} \mathrm{R}{ }_{\mathrm{j}}^{\mathrm{s}} \eta_{\mathrm{j}}$ \\
energy balance & $\mathrm{Nf}_{\mathrm{h}}\left(\theta_{\mathrm{s}}-\theta_{\mathrm{b}}\right)=\mathrm{Da} \sum_{\mathrm{j}=1}^{2} \mathrm{~B}_{\mathrm{j}} \mathrm{R}{ }_{\mathrm{j}}^{\mathrm{s}} \eta_{\mathrm{j}}$
\end{tabular}

mass balance Catalyst Particle (Slab Geometry)

$$
\begin{array}{ll}
\text { mass balance } & \frac{d^{2} f_{i, p}}{d r_{p}^{* 2}}-2 \lambda_{m, i} \frac{d f_{i, p}}{d r_{p}^{*}}+4 \phi_{i, 0}^{2} \sum_{j=1}^{2} \alpha_{i, j} R j_{j}^{p}=0 \\
\text { boundary conditions } & \begin{array}{l}
r_{p}^{*}=0 ; f_{i, p}=f_{i, s} \\
r_{p}^{*}=1 ; f_{i, p}=f_{i, s}
\end{array}
\end{array}
$$

with

$$
\eta_{\mathrm{j}}=\frac{\int_{0}^{1} \mathrm{R}_{\mathrm{j}}^{\mathrm{p}} \mathrm{dr}_{\mathrm{p}}^{*}}{\mathrm{R}_{\mathrm{j}}^{\mathrm{s}}}=\frac{\mathrm{R}_{\mathrm{obs}, \mathrm{j}}}{\mathrm{R}_{\mathrm{j}}^{\mathrm{s}}}
$$

and

$$
\mathrm{j}=\text { number of the reaction }
$$$$
\mathrm{j}=\text { methanol or formal dehyde }
$$$$
\text { Model Parameters }
$$

$\mathrm{Nf}_{\mathrm{M}}=$ 95.5; $\mathrm{Nf}_{\mathrm{F}}=100.4 ; \mathrm{Nf}_{\mathrm{h}}=118.7 ; \mathrm{N}_{\mathrm{w}}=11.49$;

$\mathrm{Da}=1.04(2.08)^{\mathrm{a}} ; \mathrm{B}_{1}=0.729 ; \mathrm{B}_{2}=1.071 ; \theta_{\mathrm{w}}=1.0 ;$

$\lambda_{\mathrm{m}, \mathrm{M}}=\lambda_{\mathrm{m}, \mathrm{F}}=10$ (for HT1D dc model); $\lambda_{\mathrm{m}, \mathrm{M}}=\lambda_{\mathrm{m}, \mathrm{F}}=$

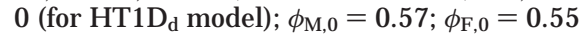

a Damkohler number is 1.04 on the first zone of the reactor and 2.08 on the second zone.

also considered:

$$
\begin{aligned}
\mathrm{CH}_{3} \mathrm{OH}+{ }^{1} / 2 \mathrm{O}_{2} \rightarrow \mathrm{CH}_{2} \mathrm{O}+\mathrm{H}_{2} \mathrm{O} ; \underset{\mathrm{CH}_{2} \mathrm{O}}{\mathrm{CH}_{2} \mathrm{O}_{2}} \rightarrow \mathrm{CO}+\mathrm{H}_{2} \mathrm{O}
\end{aligned}
$$

The kinetic models chosen to describe the reaction system were $\mathrm{e}^{33,34}$

$$
R_{1}=k_{1}(T) P^{0.75} \frac{Y_{M}{ }^{0.75}}{\left(1+Y_{M}{ }^{0.5}\right)^{0.5}} ; \quad R_{2}=k_{2}(T) P_{C_{2} \mathrm{O}}
$$

with

$$
\begin{gathered}
\mathrm{k}_{1}(\mathrm{~T})=\mathrm{k}_{0,1} \mathrm{e}^{\left(-\mathrm{E}_{\mathrm{a}, 1} / \mathrm{RT}\right)} ; \quad \mathrm{k}_{2}(\mathrm{~T})=\mathrm{k}_{0,2} \mathrm{e}^{\left(-\mathrm{E}_{\mathrm{a}, 2} / \mathrm{RT}\right)} \\
\mathrm{E}_{\mathrm{a}, 1}=36786 \mathrm{~J} / \mathrm{mol} ; \\
\mathrm{k}_{0,1}=2.92 \times 10^{2} \mathrm{~mol} / \mathrm{kg} \cdot \mathrm{s} \cdot \mathrm{atm}^{0.75} ; \\
\mathrm{E}_{\mathrm{a}, 2}=66413 \mathrm{~J} / \mathrm{mol} ; \mathrm{k}_{0,2}=3.00 \times \\
10^{3} \mathrm{~mol} / \mathrm{kg} \cdot \mathrm{s} \cdot \mathrm{atm}
\end{gathered}
$$

Industrially, this process takes place at atmospheric pressure and at an inlet temperature of $530 \mathrm{~K}$. The reactor modeling only considers a single-tube reactor $(\mathrm{L}$ $=0.75 \mathrm{~m} ; \mathrm{d}_{\mathrm{t}}=0.021 \mathrm{~m}$ ), which has two distinct catalytic zones: a less active bed in the first region of the reactor ( $0.2 \mathrm{~m}$ of catalyst diluted with $50 \%$ inert) and a second zone with pure catalyst $(0.55 \mathrm{~m})$. In the mathematical equations this feature is taken into account through the bulk density $\rho_{\mathrm{b}}\left(\mathrm{kg}_{\text {catalyst }} / \mathrm{m}^{3}\right.$ reactor $)$, which is twice as high in the second zone. This activity profile of the catalytic bed allows lower heat release and a reduction in the parametric sensitivity to temperature runaway when compared with uniform-activity reactors.

Different reactor models were used: one-dimensional pseudo-homogeneous model, PHID, one-dimensional heterogeneous models with intraparticle diffusion $\left(H T 1 D_{d}\right)$ and with intraparticle diffusion and convection $\left(H T 1 D_{d c}\right)$, and also a two-dimensional heterogeneous model with internal diffusion $\left(\mathrm{HT}_{2} \mathrm{D}_{d}\right)$. The balance equations of the one-dimensional models are described in Table 1 where the system parameters are also referenced. On the heterogeneous models the catalyst particles were assumed with isothermal behavior and the intraparticle convection was considered through the mass intraparticle Peclet number, $\lambda_{\mathrm{m}, \mathrm{i}}$, which reflects the influence of the convective/diffusional mass transport; $\lambda_{\mathrm{m}, \mathrm{i}}=0$ for the HT1D $\mathrm{d}$ model and $\lambda_{\mathrm{m}, \mathrm{l}}=10$ for the HT1D dc model. For the PHID model, only the fluidphase balances are taken into account (eqs 1-3), considering the effectiveness factors of the catalyst particles for both reactions equal to $1, \eta_{\mathrm{j}}=1$. When the radial gradients were considered, HT2D models, the classical dispersions terms were included in the bal ance equations and the Péclet and Biot numbers used on our work were $P e_{m r}\left(d_{p}\right)=8.7, P e_{r r}\left(d_{p}\right)=2.6$, and $B_{i}=1.3$.

The differential selectivity, $S^{\prime}{ }_{1,2}$, differential yield, $\Phi^{\prime}$, integral yield, $\Phi$, and conversion of methanol, $X_{M}$, and formal dehyde, $X_{F}$, were defined through the following equations:

$$
\begin{array}{r}
S_{12}^{\prime}=\frac{R_{o b s, 1}-R_{o b s, 2} ; \quad R_{o b s, 2}=\frac{R_{o b s, 1}-R_{o b s, 2}}{R_{o b s, 1}} ;}{\Phi=\frac{F_{F}-F_{F 0}}{F_{M 0}-F_{M}}} \\
X_{M}=\frac{F_{M, 0}-F_{M}}{F_{M, 0}} ; X_{F}=\frac{F_{F, 0}+X_{M} F_{M, 0}-F_{F}}{F_{F, 0}+X_{M} F_{M, 0}}
\end{array}
$$

For the GPSC, the normalized objective sensitivity is defined by the following equation:

$$
\mathbf{S}\left(\theta_{\mathrm{s}}^{*} ; \phi_{\mathrm{i}}\right)=\frac{\phi_{\mathrm{i}}}{\theta_{\mathrm{s}}^{*}} \frac{\partial \theta_{\mathrm{s}}^{*}}{\partial \phi_{\mathrm{i}}}=\frac{\partial \ln \theta_{\mathrm{s}}^{*}}{\partial \ln \phi_{\mathrm{i}}}
$$

where $\theta_{\mathrm{s}}{ }^{*}$ is the normalized catalyst temperature at the hot spot and $\phi_{\mathrm{i}}$ represents an inlet parameter defined in the model equations. When the pseudo-homogeneous models are used, $\theta_{\mathrm{s}}{ }^{*}$ should be replaced by $\theta^{*}$ which is the normalized bulk temperature at the hot spot.

The critical values of the operating conditions, such as feed temperature concentration, which separate runaway from stable reactor behavior, are those which correspond to a maximum sensitivity. This criterion has a generalized character because it does not depend on the particular input parameter chosen to calculate the sensitivity function, and so, any of the several dimensionless parameters that define the model could be used. Nevertheless, in a previous work (Quina and Quinta Ferreira ${ }^{35}$ ) it was shown that the most influential parameter is the dimensionless wall temperature, $\theta_{\mathrm{w}}$, and therefore, the normalized objective sensitivity was mainly calculated in respect to this parameter. The methodol ogy adopted to establish the runaway diagrams can be resumed in the following steps: (1) for a given inlet temperature $T_{0},(2)$ and a given inlet reactant concentration, $C_{M, 0}$, (3) the state equations were inte- 


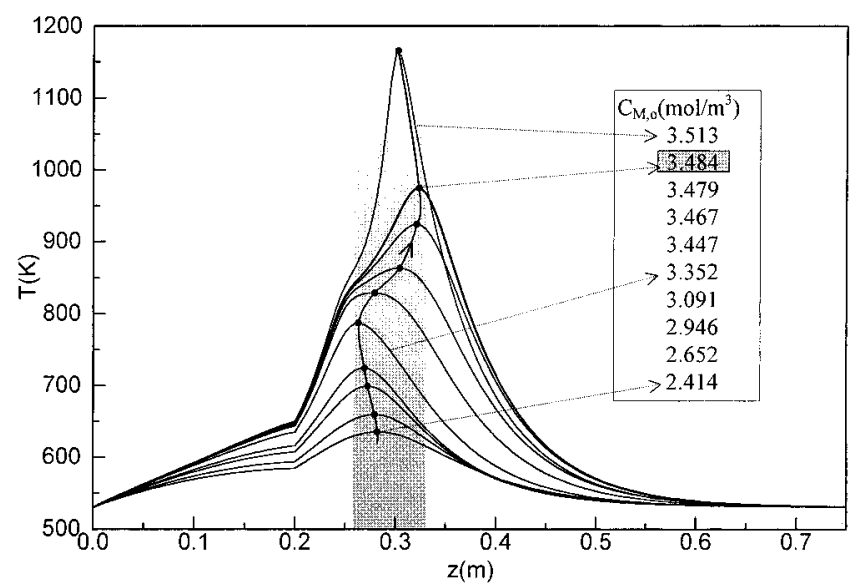

Figure 1. Axial temperature profiles predicted with the $\mathrm{PH} 1 \mathrm{D}$ model, for various inlet concentrations and for $T_{0}=T_{w}=530 \mathrm{~K}$. The profile related to $C_{M, 0}=3.484 \mathrm{~mol} / \mathrm{m}^{3}$ corresponds to the critical conditions.

grated (using the DDASAC package ${ }^{36}$ ) and simultaneously the sensitivity functions were calculated, until the hot spot temperature was reached; the sensitivity coefficient, $\mathbf{S}\left(\theta_{\mathrm{s}} * ; \theta_{\mathrm{w}}\right)$, related to those inlet conditions $\left(T_{0} ; C_{M, 0}\right)$ was obtained. (4) The inlet reactant concentration, $C_{M, 0}$, was increased and step (3) was performed again. (5) The normalized objective sensitivity, $\mathbf{S}\left(\theta_{\mathrm{s}}{ }^{*} ; \theta_{\mathrm{w}}\right)$, of two successive iterations, was compared:

if a maximum is attained in the $\mathbf{S}\left(\theta_{\mathrm{s}}^{*} ; \theta_{\mathrm{w}}\right)$, then the critical conditions are those operating conditions ( $T_{0}$; $C_{M, 0}$ ) which correspond to this value of sensitivity;

otherwise, calculations would proceed with step (4).

(6) To obtain the entire runaway diagram, steps (1)(5) should be repeated for different inlet temperatures, $\mathrm{T}_{0}$.

\section{Computer Results}

As referred to before, the reactor has two distinct zones with different activity: $0.20 \mathrm{~m}$ of catalyst diluted with $50 \%$ of inert at the entrance and $0.55 \mathrm{~m}$ of pure catalyst at the exit. When $T_{0}=530 \mathrm{~K}$, Figure 1 represents the axial temperature profiles, which were obtained through the pseudo-homogeneous model with different inlet methanol concentrations. For methanol concentrations close to $3.48 \mathrm{~mol} / \mathrm{m}^{3}$, the increase of the hot spot temperature, $T_{\max }$, is higher Figure $2 \mathrm{a}$. The system sensitivity reaches a maximum in this point, Figure $2 b$, for any of the inlet parameters, revealing then the generalized character of this method. Therefore, the system is considered under runaway conditions when the dimensionless heat parameter corresponding to the main reaction, $\mathrm{S}$, is higher than 1.05 (i.e., $\mathrm{C}_{\mathrm{M}, 0}$ $>3.48 \mathrm{~mol} / \mathrm{m}^{3}$ ). In this case the hot spot is located on the second zone of the reactor and, for lower inlet concentrations, its increase leads to a displacement toward the reactor inlet. Afterward, an inverse displacement toward an inner zone of the reactor takes place, which is due to the onset of the second reaction. In fact, neglecting the formaldehyde oxidation through the side reaction, we have observed that the location of the hot spots were al ways closer to the reactor entrance when the methanol concentration in the feed was higher. When the maximum sensitivity is approached, almost all the methanol is converted to formal dehyde through the second reaction (Figure 2c) and a sharp decrease of the differential and integral yields calculated under hot

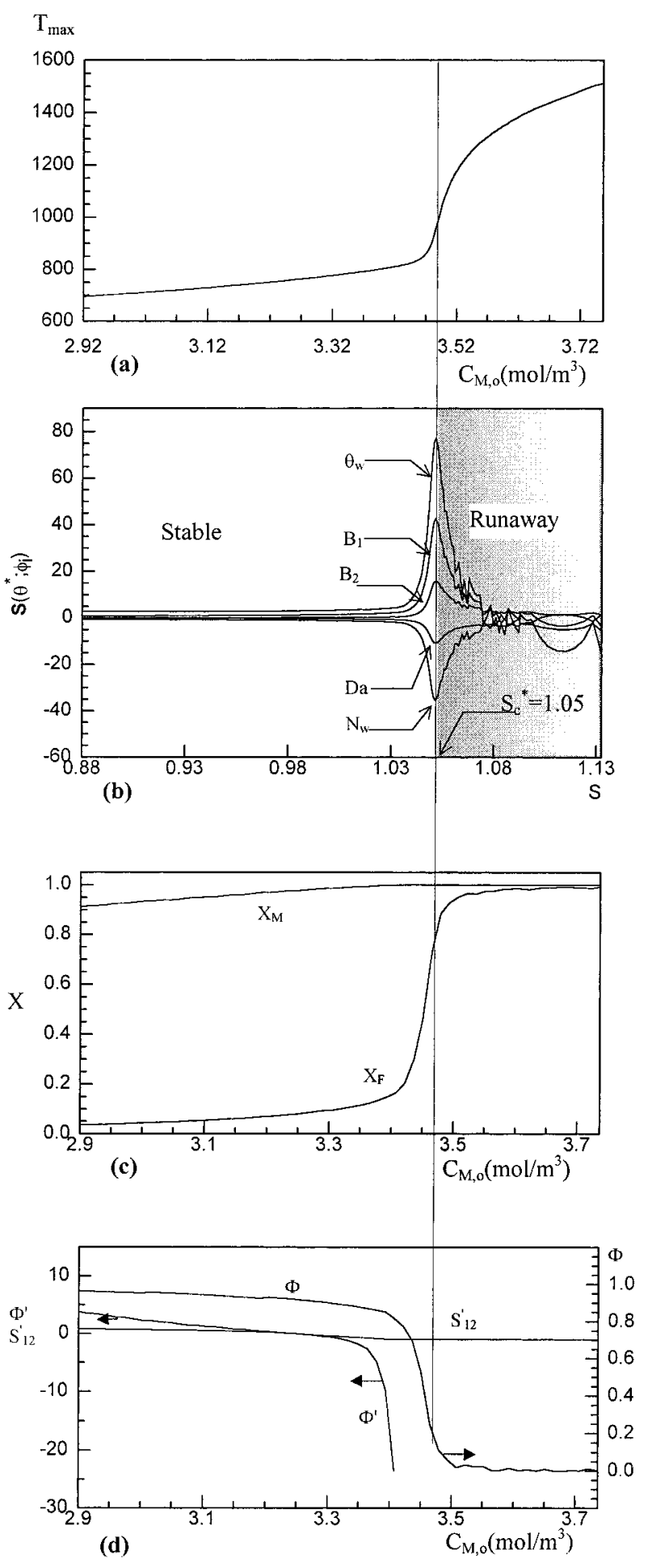

Figure 2. Results obtained through the PHID model with $\mathrm{T}_{0}=$ $530 \mathrm{~K}$ : (a) Temperature of the hot spot vs inlet methanol concentration; (b) normalized objective sensitivity related to the PHID model parameters vs dimensionless heat of the main reaction; (c) methanol and formaldehyde conversions vs feed reactant concentration; (d) differential selectivity, $\mathrm{S}_{12}^{\prime}$, differential yield, $\Phi^{\prime}$, and integral yield, $\Phi$, on the hot spot conditions vs inlet methanol concentration.

spot conditions, $\Phi^{\prime}$ and $\Phi$, is observed (Figure $2 \mathrm{~d}$ ). In fact, the high temperatures associated with the runaway conditions favor the secondary reaction, which becomes then the reaction that determines the runaway behavior of the system. It is therefore important to consider the side reactions in these studies, even when it seems they are not so important for the overall behavior of the 

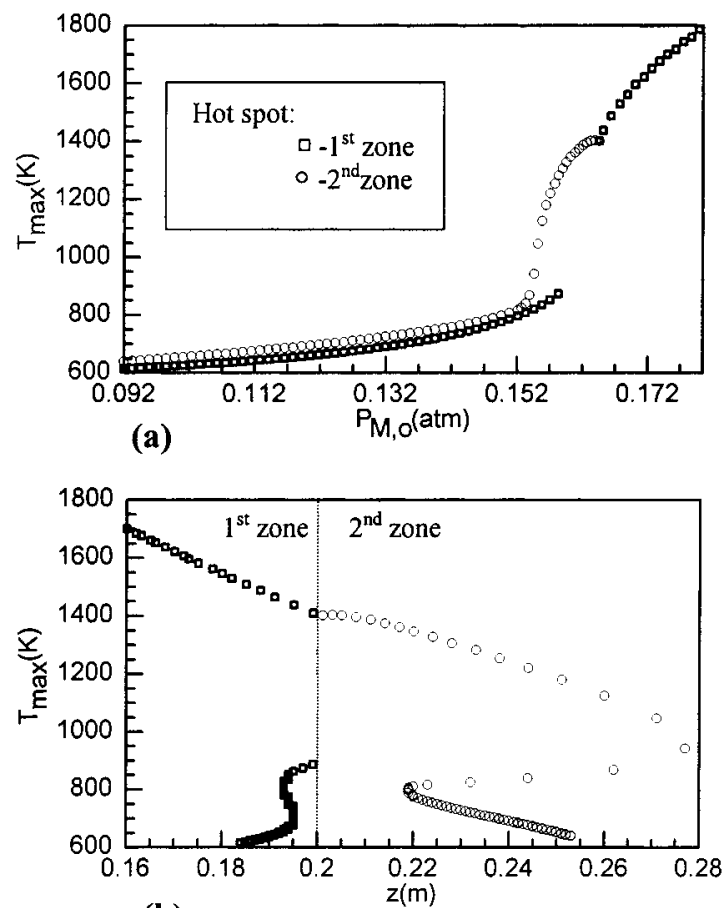

(b)

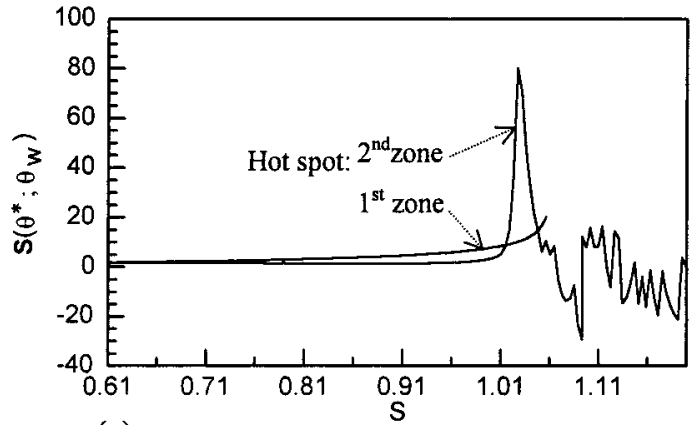

(c)

Figure 3. Results obtained through the PHID model and $\mathrm{T}_{0}=$ $550 \mathrm{~K}$ : (a) Hot spot temperature vs partial inlet pressure of the methanol; (b) hot spot temperatures vs axial position of the reactor; (c) normalized objective sensitivity of the temperature related to the wall temperature, for the two hot spots.

system, as we concluded when the study of the parametric sensitivity was performed (Quina and Quinta Ferreira ${ }^{35}$ ).

A peculiar behavior of the system due to the presence of two distinct zones on the catalytic bed was observed through our results. For certain operating conditions two hot spots can be devel oped on the fixed- bed reactor, one on each zone, as it can be seen in Figure 3 for $\mathrm{T}_{0}=$ $550 \mathrm{~K}$ and Figure 4 for $\mathrm{T}_{0}=570 \mathrm{~K}$. In the first case, one can observe in Figure $3 a$ that when $\mathrm{P}_{\mathrm{M}, 0}<0.159$ atm, one hot spot is developed in the first zone of the bed and a higher one on the second region, it being possible to observe their displacement along the bed in Figure 3b. Afterward, only one hot spot is observed in the second zone because the temperature al ong the first zone increases without reaching a maximum and only in the second zone is a maximum value attained. However, for still higher methanol concentrations $\left(P_{M, 0}\right.$ $>0.164$ atm) the unique hot spot of the system develops in the first zone. In Figure 3c, one can see that for low $S$ values (low $P_{M, 0}$ values) the sensitivity related to the hot spot of the second zone is lower than the one associated with the hot spot of the first region. Never-
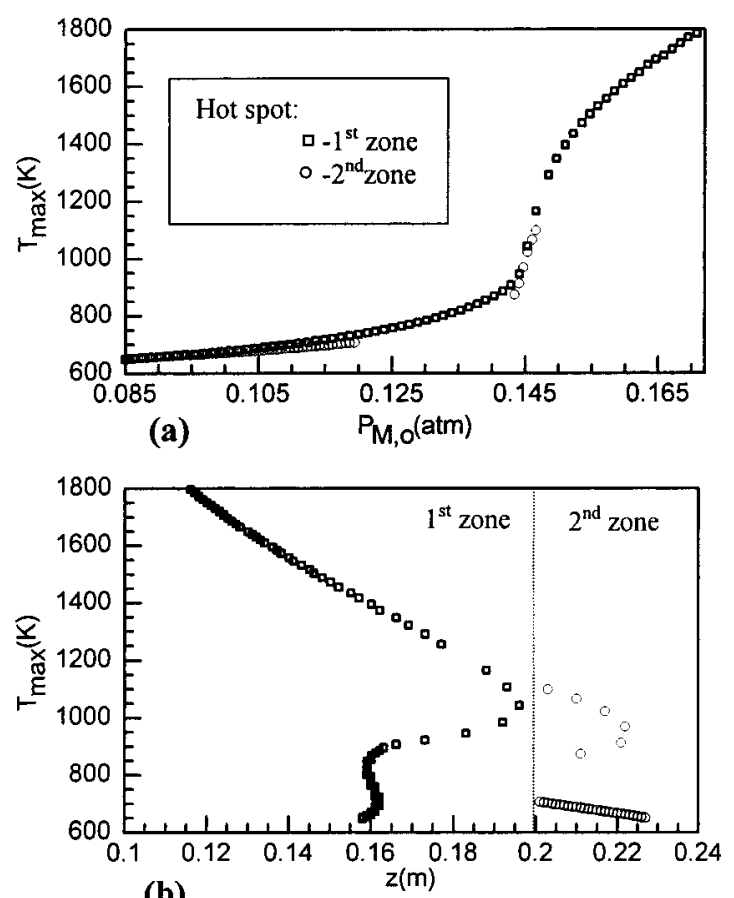

(b)

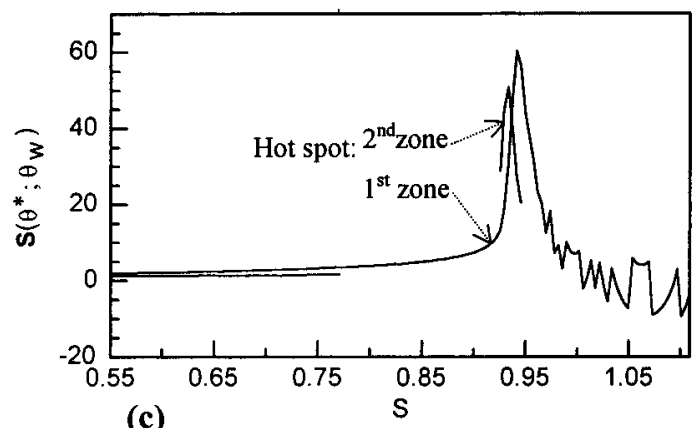

Figure 4. Results obtained through the PHID model and $\mathrm{T}_{0}=$ $570 \mathrm{~K}$ : (a) Hot spot temperature vs partial inlet pressure of the methanol; (b) hot spot temperatures vs axial position of the reactor; (c) normalized objective sensitivity of the temperature related to the wall temperature, for the two hot spots.

theless, it is that one that first becomes particularly sensitive (reaching a maximum for $S=1.03$ ), it being then the hot spot associated with the second zone that determines the critical operating conditions for the system. F or an inlet temperature of $570 \mathrm{~K}$, two hot spots for lower inlet concentrations can also be observed when $\mathrm{P}_{\mathrm{M}, 0}<0.12$ atm, and afterward, only in the first region of the bed a maximum temperature value is detected, followed again by two hot spots when $P_{M, 0}$ is between 0.144 and 0.147 atm; after this value only the first region shows a maximum in the temperature profile, Figure $4 a, b$. The runaway temperature is established by the hot spot on the second zone because the corre sponding maximum of the sensitivity function occurs for slightly milder operating conditions (lower reactant concentration) (Figure 4c). Therefore, when the reactor has two distinct catalytic zones, it will be important to foll ow the two hot spots because one or the other can lead to the runaway phenomenon.

To obtain the runaway diagrams, the system behavior was studied in a range of inlet temperatures of 440$700 \mathrm{~K}$. F or different inlet temperatures and concentrations, the normalized objective sensitivity profiles, $\mathbf{S}\left(\theta^{*} ; \theta_{\mathrm{w}}\right)$ are represented in Figure 5 versus the heat released by the first reaction, $S$ (successive increases 


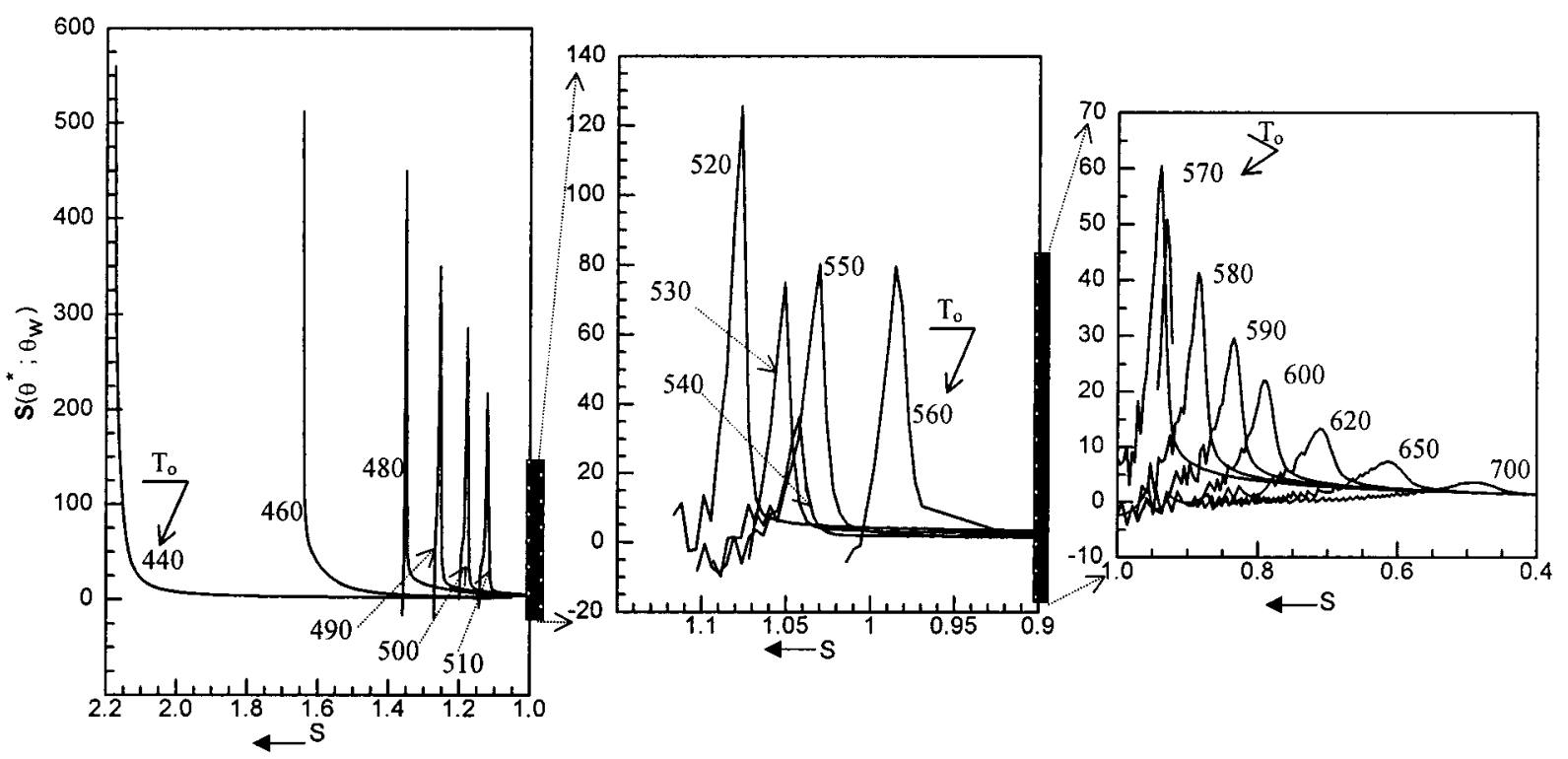

Figure 5. Sensitivity of the hot spot, $\theta^{*}$, related to the wall temperature, $\theta_{\mathrm{w}}$, predicted with the PH1D model for different inlet temperatures $\left(T_{0}=440-700 \mathrm{~K}\right)$.

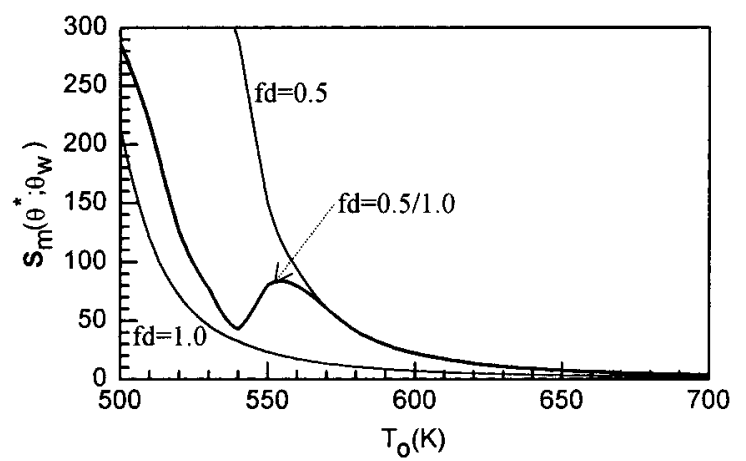

Figure 6. Normalized objective sensitivity of the hot spot temperature, PHID model for different catalytic activities of the bed $(\mathrm{fd}=0.5 / 1.0 ; \mathrm{fd}=0.5 ; \mathrm{fd}=1.0)$.

on the $\mathbf{S}\left(\theta^{*} ; \theta_{\mathrm{w}}\right)$ scale are also shown). The sharp decrease of the sensitivity at high $\mathbf{S}$ values shows that for lower inlet temperatures the temperature runaway is a violent phenomenon. When the inlet temperature is increased, the sensitivity of the hot spot decreases. However, in this system, the maximum values of the sensitivity function are lower on the temperature range of $530-540 \mathrm{~K}$. This can also be observed in Figure 6 where the maxima of the sensitivity for different inlet temperatures $\left(T_{0}>500 \mathrm{~K}\right)$ were represented in three different cases: for a fixed bed with $50 \%$ of catalyst dilution ( $\mathrm{fd}=0.5$ ), for a fixed bed with pure catalyst ( $\mathrm{fd}$ $=1.0$ ), and for a fixed bed with part of the bulk diluted in $50 \%$ inert followed by pure catalyst ( $\mathrm{fd}=0.5 / 1.0$ ). One can observe that when the bed is partially diluted, the sensitivity has a minimum which corresponds to a transition of the influence on the reactor behavior of one of the zones to the other. In fact, for mild operating conditions (low inl et temperatures) the second catalytic zone ( $\mathrm{fd}=1.0$ ) of the reactor dominates the reactor behavior, and for severe operating conditions the overall behavior of the reactor is controlled by the first catalytic zone ( $\mathrm{fd}=0.5$ ). Moreover, one can also conclude that the less active bed $(\mathrm{fd}=0.5)$ has higher sensitivity than the one associated with the reactor packed with pure catalyst ( $\mathrm{fd}=1.0$ ). For higher inlet temperatures the maximum sensitivity decreases, approaching zero (Fig- ures 5 and 6), which leads to the loss of generality of this criterion for low $\mathrm{S}$ values.

The boundaries between sensitive and stable reactor behavior are shown in Figures 7 and 8, where the critical operating conditions $\left(T_{0}, C_{M, 0}\right)$ were represented either directly (Figure 7) or through the dimensionless parameters $\mathrm{N}, \mathrm{S}$, and $\gamma$ (Figure 8), which correspond to the dimensionless heat-transfer parameter $\left[\mathrm{N}=4 \mathrm{U} \mathrm{C}_{\mathrm{M}, 0} /\right.$ $\left.\mathrm{d}_{\mathrm{t} \rho_{\mathrm{f}}} \mathrm{C}_{\mathrm{p}} \rho_{\mathrm{b}} \mathrm{R}_{1,0}\right]$, dimensionless main reaction heat parameter [S $\left.=(-\Delta \mathrm{H})_{1} \mathrm{C}_{\mathrm{M}, 0} / \rho_{\mathrm{f}} \mathrm{C}_{\mathrm{p}_{\mathrm{f}}} \mathrm{T}_{0}\right]$, and Arrhenius number $\left[\gamma=E_{a, 1} / R_{0}\right]$, respectively. From Figure 7 one can conclude that, for low temperatures, the system studied with catalyst dilution in the first zone of the reactor ( $\mathrm{fd}$ $=0.5 / 1.0$ ) leads to a behavior identical to the one predicted by a pure catalyst ( $\mathrm{fd}=1.0$ ), this behavior being the behavior of an entirely diluted bed $(f d=0.5)$ approached for high temperatures. Moreover, for less active beds the stability is higher because the stable zone is larger, which corresponds to a gain in the critical methanol concentration of $20 \%$ for a feed temperature of $530 \mathrm{~K}$. For higher inlet temperatures it was possible to observe gains of $40 \%$. Figure 8 corresponds to a classical runaway diagram which was first presented by Barkelew, ${ }^{37}$ where continuous lines represent the boundaries between the safe region and the runaway region for different catalytic activity profiles, and the dashed lines joined points that are related to the same inlet temperature. In this diagram we represented two curves for the partially diluted bed. For the curve corresponding to $\mathrm{fd}=0.5 / 1.0$, we used the bulk density $\rho_{\mathrm{b}}$ of the diluted bed $\left(\mathrm{fd}=0.5 ; \rho_{\mathrm{b}}=550 \mathrm{~kg} / \mathrm{m}^{3}\right.$ ) to calculate the parameter $\mathrm{N}$, which allows a direct comparison of the stable and unstable regi ons obtained for the partially and totally diluted beds. F or the curve corresponding to $\mathrm{fd}^{*}=0.5 / 1.0$, the bulk density $\rho_{\mathrm{b}}$ of the pure catalytic bed $\left(\mathrm{fd}=1.0 ; \rho_{\mathrm{b}}=1100 \mathrm{~kg} / \mathrm{m}^{3}\right)$ was considered for calculating $\mathrm{N}$, allowing then a comparison with the results obtained when no dilution is taken into account. Therefore, the shadow zone marked with the circled " 1 " shows the loss in terms of stability of the system studied with two catalytic zones in respect to a reactor where all the bed is diluted ( $\mathrm{fd}=0.5$ ). The shadow zone marked with a circled " 2 " shows the gain 


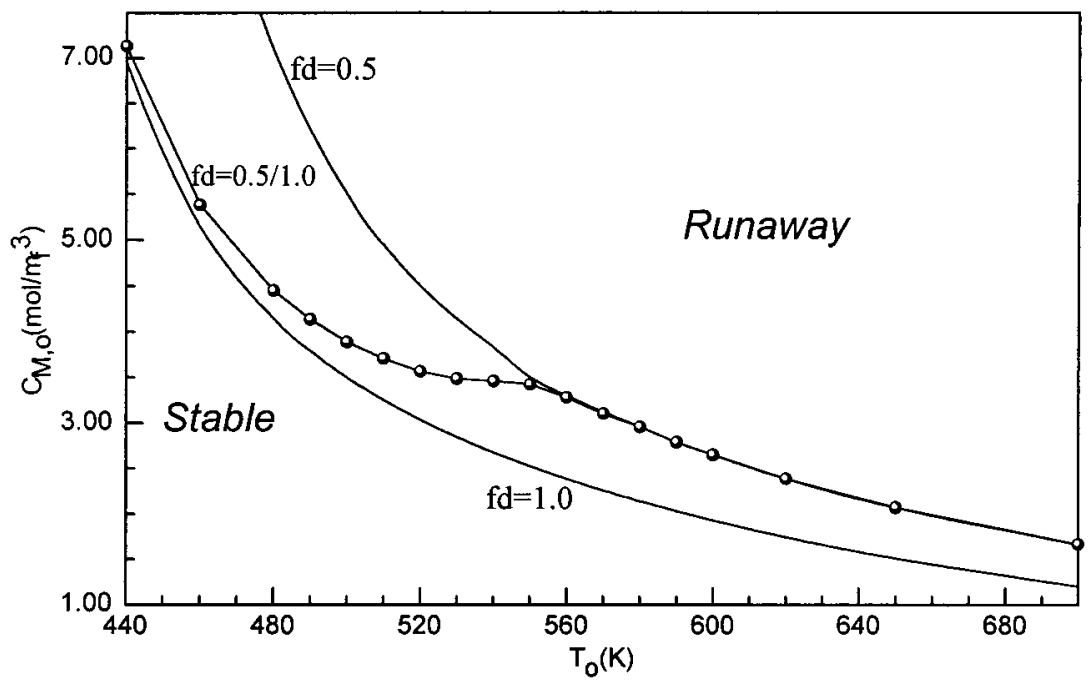

Figure 7. Reactant concentration, $\mathrm{C}_{\mathrm{M}, 0}$, vs feed temperature, $\mathrm{T}_{0}$, corresponding to the critical conditions, PH1D model, to different catalytic activities: $\mathrm{fd}=1.0 ; \mathrm{fd}=0.5 / 1.0 ; \mathrm{fd}=0.5$.

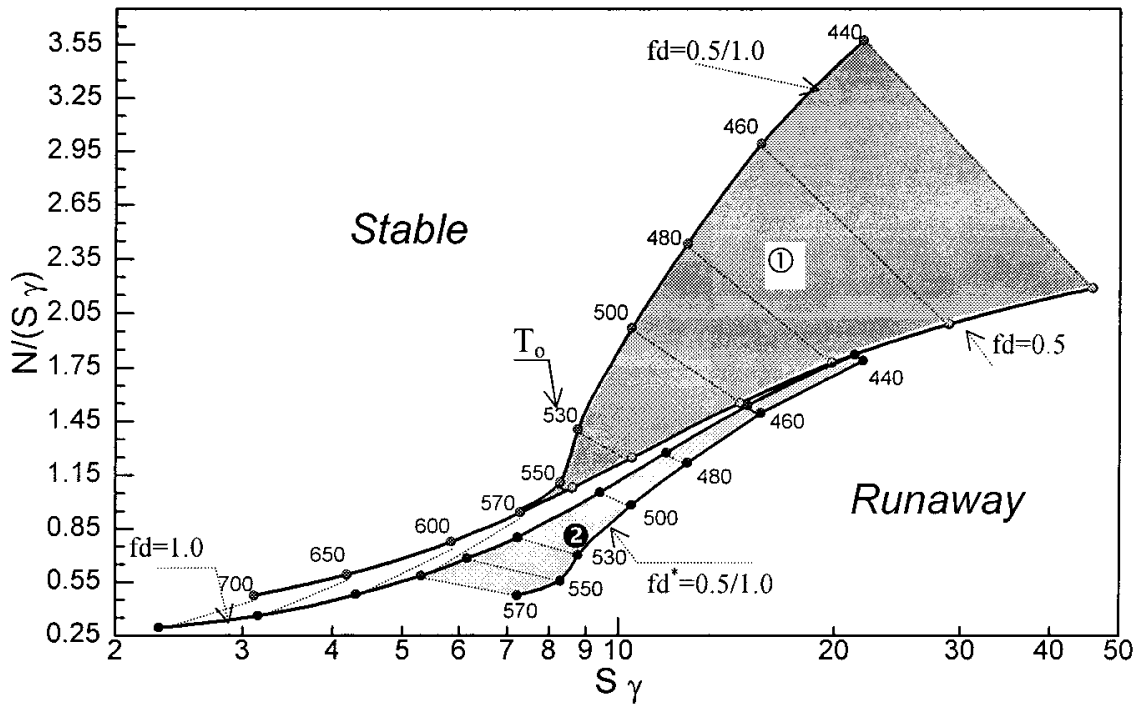

Figure 8. Diagram of the critical conditions predicted with the PH1D model, for different catalytic activities: $f d=1.0 ; \mathrm{fd}=0.5 / 1.0 ; \mathrm{fd}$ $=0.5$.

in terms of stability when the system studied is compared with only pure catalyst ( $\mathrm{fd}=1.0)$.

The runaway diagrams of Figure $9 a, b$ show the comparison between the predictions of pseudo-homoge neous and heterogeneous models. For the two-dimensional model, the critical conditions were calculated with the sensitivity corresponding to the reactor axis because it is higher than that of the other radial positions (Quina and Quinta Ferreira35). When the heterogeneous models are used, the resistances to mass transfer either inside the particles or in the interface fluid/solid leads to a decrease of the reactant concentration in the catalyst. Lower reaction rates will also occur then with lower heat released in the system when compared with the predictions of the pseudo-homogeneous model. So, when the mass resistances are dominant in the overall behavior of the system, the critical conditions are reached for higher inlet concentrations and temperatures, the heterogeneous model then being less conservative. However, when the thermal resistances superimpose the mass resistances, which can happen in our study only in the interface fluid/solid because the catalyst particles were considered with isothermal behavior, higher temperatures in the solid can be developed. Consequently, higher quantities of heat can be released from the reactional process because of the increase of the reaction rates. In these situations the heterogeneous model will reach the runaway conditions for lower operating conditions, the pseudo-homogeneous model then being less conservative. This occurs on the range of low inlet temperatures or high $\mathrm{S} \gamma$ values, as can be seen in Figure 9. In fact, one can observe that for mild conditions the most conservative is the HT2 $D_{d}$ model, but for severe conditions (lower $\mathrm{S} \gamma$ values) the PH ID model becomes more conservative. Despite the great differences in what concerns the mathematical complexity, the different models predicted similar qualitative boundaries for the runaway and stable zones. However, it is our belief that when possible the HT2D model should be used to predict the critical conditions. In fact, this model being more conservative than the others for mild conditions (low inlet temperatures or high $\mathrm{S} \gamma$ ), when the runaway phenomenon is more violent, it will be convenient to perform a more thorough analysis of the system behavior.

Several studies have shown the importance of the additional mass flux by convection inside catalysts. ${ }^{11,38-42}$ Namely, it was possible to get the same level of the 

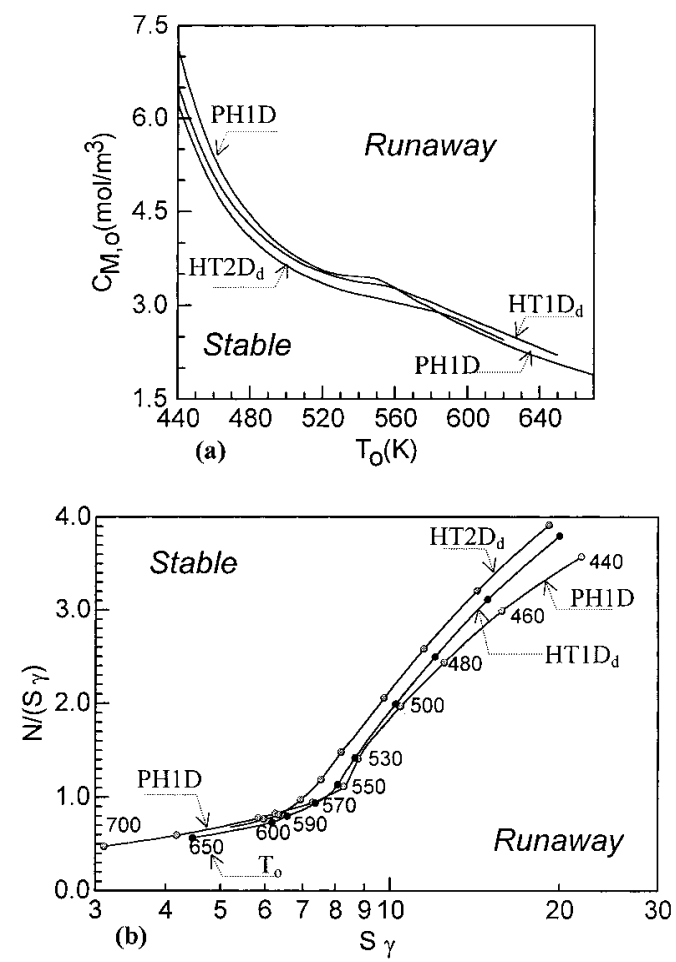

Figure 9. Diagrams of the critical conditions, predicted with the HT2D, HT1D , and PH1D models: (a) Inlet reactant concentration vs feed temperature; (b) ratio between the dimensionless heattransfer parameter and the dimensionless main reaction heat parameter vs dimensionless main reaction heat parameter.

reactant conversion under softer inlet conditions. In a previous work, dealing with o-xylene oxidation to phthalic anhydride, Quinta Ferreira et al. ${ }^{43}$ said that when intraparticle convection is considered, the establishment of the critical conditions could be ambiguous because more than one maximum in the sensitivity function could be observed for some operating conditions. However, for the system of the oxidation of methanol to formaldehyde only one maximum was observed. This must be due to the lower exothermicity of the methanol reaction and also the lower activity of the diluted bed at the entrance of the reactor. Figure 10 shows that the influence of the intraparticular convection is important in all the ranges of the inlet temperatures analyzed, the system becoming more sensitive when the additional mass flux by convection is considered. The approximation of the two lines, in the neighborhood of the inlet temperature of $550 \mathrm{~K}$, is a consequence of the transition of the influence from the second to the first reactor zone.

\section{Conclusions}

The main objective of the present paper is centered on the analysis of safe and runaway regions of a partially diluted catalytic bed of a fixed-bed reactor, by using the Generalized Parametric Sensitivity Criterion. The main advantages of this method are based on the exact concept of parametric sensitivity and on its generalized character in respect to any of the inlet parameters of the mathematical models.

The system of the methanol oxidation to formaldehyde was studied, through different mathematical models: a one-dimensional pseudo-homogeneous model, one-dimensional heterogeneous model, and two-dimensional heterogeneous model. F or the heterogeneous models the effect of the intraparticle convection on the reactor
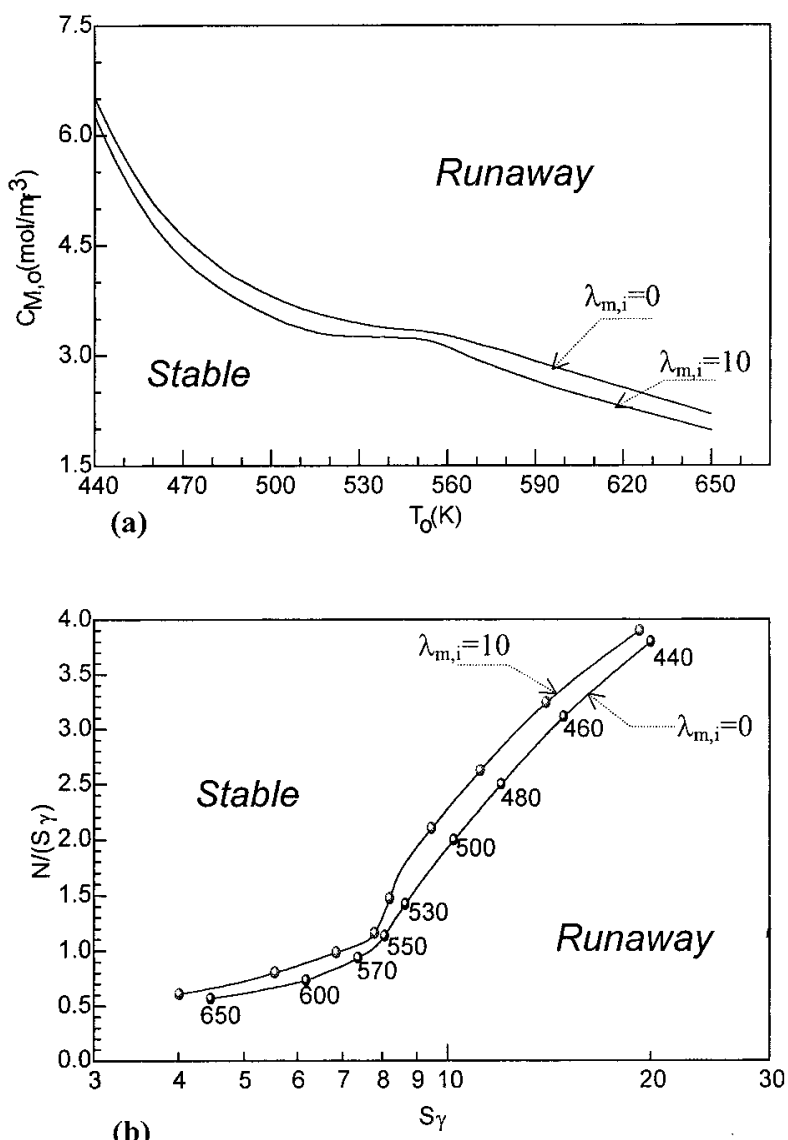

Figure 10. Diagrams of the critical conditions, predicted with the HT1D and HT1D dc models: (a) inlet reactant concentration vs feed temperature; (b) ratio between the dimensionless heattransfer parameter and the dimensionless main reaction heat parameter vs dimensionless main reaction heat parameter.

behavior was also analyzed. Our results showed that, for runaway predictions, it is very important to take into account the side reaction involving the formal dehyde oxidation because it is responsible for the occurrence of the temperature runaway. I n fact, because of its higher activation energy, it becomes more sensitive to temperature variations, when methanol is almost completely converted into formaldehyde.

An important decrease on the parametric sensitivity of the process to temperature runaway is obtained when a less active catalytic bed is used in the initial part of the reactor, and a minimum on the normalized objective sensitivity for the range of inlet temperatures usually used on the industry is observed. This means that the industrial reactor with two different catalytic activity zones is operating under stability advantages. The heterogeneous models are recommended for studying the temperature runaway because they are more conservative for mild conditions, when the runaway is an important phenomenon. Moreover, the system becomes more sensitive, when the additional mechanism of transport inside the solid, intraparticle convection is considered. However, milder operating conditions can be used to achieve the same conversion as the one obtained when only internal diffusion is taken into account.

\section{Nomenclature}

$A_{p}=$ specific particle area, $m^{-1}$

$a_{v}=$ specific particle area (referred to the reactor volume) $\left[\left(1-\epsilon_{b}\right) A_{p}\right], m^{-1}$ 
$B \mathrm{i}_{\mathrm{w}}=$ wall heat Biot number, $\left[\mathrm{h}_{\mathrm{w}} \mathrm{R}_{\mathrm{t}} / \lambda_{\mathrm{er}}\right]$

$\mathrm{B}_{\mathrm{j}}=$ adiabatic temperature rise, $\left[(-\Delta \mathrm{H})_{\mathrm{j}} \mathrm{C}_{\mathrm{M}, 0} / \rho_{\mathrm{f}} \mathrm{C}_{\mathrm{p}_{\mathrm{f}}} \mathrm{T}_{0}\right]$

$\mathrm{C}_{\mathrm{i}, \mathrm{b}}=$ concentration of component $\mathrm{i}$ at the bulk, $\mathrm{mol} / \mathrm{m}^{3}$

$\mathrm{C}_{\mathrm{i}, 0}=$ feed concentration of component $\mathrm{i}, \mathrm{mol} / \mathrm{m}^{3}$

$\mathrm{C}_{\mathrm{i}, \mathrm{p}}=$ concentration of component $\mathrm{i}$ inside the catalyst, $\mathrm{mol} /$ $\mathrm{m}^{3}$

$\mathrm{C}_{\mathrm{i}, \mathrm{s}}=$ concentration of component $\mathrm{i}$ at the catalyst surface, $\mathrm{mol} / \mathrm{m}^{3}$

$\mathrm{C}_{\mathrm{M}, 0}=$ feed methanol concentration, $\mathrm{mol} / \mathrm{m}^{3}$

$\mathrm{C}_{\mathrm{p}_{\mathrm{f}}}=$ heat capacity of the fluid, $\mathrm{J} / \mathrm{kg} \cdot \mathrm{K}$

$\mathrm{Da}=$ Damköhler number, $\left[\mathrm{L} \rho_{\mathrm{b}} \mathrm{R}_{1,0} / \mathrm{U}_{0} \mathrm{C}_{\mathrm{M}, 0}\right]$

$D_{e, i}=$ effective diffusivity for component $i$ in the catalyst, $\mathrm{m}^{2} / \mathrm{s}$

$D_{\mathrm{er}}=$ effective radial dispersion, $\mathrm{m}^{2} / \mathrm{s}$

$\mathrm{d}_{\mathrm{p}}=$ diameter of the catalyst particle, $\mathrm{m}$

$d_{t}=$ diameter of the reactor tube, $m$

$E_{a}=$ activation energy, J/mol

$\mathrm{F}_{\mathrm{F}}=$ molar flow of formaldehyde, $\mathrm{mol} / \mathrm{s}$

$F_{F, 0}=$ molar flow of formaldehyde in the inlet conditions, $\mathrm{mol} / \mathrm{s}$

$\mathrm{F}_{\mathrm{M}}=$ molar flow of methanol, $\mathrm{mol} / \mathrm{s}$

$\mathrm{F}_{\mathrm{M}, 0}=$ molar flow of methanol in the inlet conditions, $\mathrm{mol} / \mathrm{s}$

$\mathrm{fd}=$ dilution factor (catalyst/(inert + catalyst))

$\mathrm{f}_{\mathrm{i}, \mathrm{b}}=$ dimensionless concentration of component $\mathrm{i}$ in the bulk, $\left[\mathrm{C}_{\mathrm{i}, \mathrm{b}} / \mathrm{C}_{\mathrm{M}, 0}\right]$

$\mathrm{f}_{\mathrm{i}, \mathrm{p}}=$ dimensionless concentration of component $\mathrm{i}$ in the particle, $\left[\mathrm{C}_{\mathrm{i}, \mathrm{p}} / \mathrm{C}_{\mathrm{M}, 0}\right]$

$\mathrm{f}_{\mathrm{i}, \mathrm{s}}=$ dimensionless concentration of component $\mathrm{i}$ at the catalyst surface, $\left[\mathrm{C}_{\mathrm{i}, \mathrm{s}} / \mathrm{C}_{\mathrm{M}, 0}\right]$

$h_{f}=$ film heat-transfer coefficient, $\mathrm{J} / \mathrm{m}^{2} \cdot \mathrm{s} \cdot \mathrm{K}$

$\mathrm{h}_{\mathrm{w}}=$ wall heat-transfer coefficient, $\mathrm{J} / \mathrm{m}^{2} \cdot \mathrm{s} \cdot \mathrm{K}$

$\mathrm{k}_{\mathrm{f}, \mathrm{i}}=$ film mass-transfer coefficient for component $\mathrm{i}, \mathrm{m} / \mathrm{s}$

$\mathrm{k}_{\mathrm{i}}(\mathrm{T})=$ kinetic constant

$\mathrm{L}=$ reactor length, $\mathrm{m}$

$\mathrm{N}=$ dimensionless heat-transfer parameter, [4UC $\mathrm{C}_{\mathrm{M}, 0} /$ $\left.\mathrm{d}_{\mathrm{t}} \rho_{\mathrm{f}} \mathrm{C}_{\mathrm{p} f} \rho_{\mathrm{b}} \mathrm{R}_{1,0]}\right]$

$\mathrm{Nf}_{\mathrm{h}}=$ number of film heat-transfer units, $\left[\mathrm{h}_{\mathrm{f}} \mathrm{a}_{\mathrm{v}} \mathrm{L} / \mathrm{U}_{0} \rho_{\mathrm{f}} \mathrm{C}_{\mathrm{p}_{\mathrm{f}}}\right]$

$\mathrm{Nf}_{\mathrm{i}}=$ number of film mass-transfer units, $\left[\mathrm{k}_{\mathrm{f}, \mathrm{a}} \mathrm{a}_{\mathrm{v}} \mathrm{L} / \mathrm{u}_{0}\right]$

$\mathrm{N}_{\mathrm{w}}=$ number of wall heat-transfer units, $\left[4 U \mathrm{U} L / \mathrm{d}_{\mathrm{t} \rho \mathrm{f}} \mathrm{C} \mathrm{p}_{\mathrm{f}} \mathrm{U}_{0}\right]$

$\mathrm{P}=$ total pressure, atm

$\mathrm{P}_{\mathrm{CH}_{2} \mathrm{O}}=$ formaldehyde partial pressure, atm

$P e_{r}\left(d_{p}\right)=$ radial heat Pedlet number based on particle diameter $\left[d_{p} u_{0} \rho_{f} C_{p_{f}} / \lambda_{e r}\right]$

$P e_{m r}\left(d_{p}\right)=$ radial mass Peclet number based on particle diameter $\left[d_{p} u_{0} / D_{e r}\right]$

$\mathrm{P}_{\mathrm{M}, 0}=$ feed methanol partial pressure, atm

$\mathrm{R}=$ ideal gas constant, $\mathrm{J} / \mathrm{mol} \cdot \mathrm{K}$

$\mathrm{R}_{1,0}=$ feed main reaction rate, $\mathrm{mol} / \mathrm{kg} \cdot \mathrm{s}$

$\mathrm{R}_{\mathrm{j}}=$ reaction rate, $\mathrm{mol} / \mathrm{kg} \cdot \mathrm{s}$

$\mathrm{R}_{\mathrm{j}} \mathrm{s}$ = reaction rate at the catalyst surface conditions, mol/ $\mathrm{kg} \cdot \mathrm{s}$

$\mathrm{R}_{\text {obs, } \mathrm{j}}=$ observed reaction rate, $\mathrm{mol} / \mathrm{kg} \cdot \mathrm{s}$

$\mathrm{R}_{\mathrm{p}}=$ half thickness of the slab catalyst, $\mathrm{m}$

$\mathrm{R}_{\mathrm{t}}=$ reactor radius, $\mathrm{m}$

$r_{p}=$ particle coordinate, $m$

$r_{p}{ }^{*}=$ dimensionless particle coordinate, $\left[r_{p} / 2 R_{p}\right]$

$R{ }_{j}{ }^{s}=$ dimensionless reaction rate $j$, at the surface catalyst conditions, $\left[R_{j}{ }^{S} / R_{1,0}\right]$

$R j^{p}=$ dimensionless reaction rate $j$, inside the catalyst $\left[R_{j} p /\right.$ $\left.R_{1,0}\right]$

$\mathrm{S}=$ dimensionless main reaction heat parameter,

$\left[(-\Delta \mathrm{H})_{1} \mathrm{C}_{\mathrm{M}, 0} / \rho_{\mathrm{f}} \mathrm{C}_{\mathrm{pf}} \mathrm{T}_{0}\right]$

$S^{\prime}{ }_{12}=$ differential selectivity, $\left[\left(R_{o b s, 1}-R_{o b s, 2}\right) / R_{o b s, 2}\right]$

$\mathrm{S}_{\mathrm{c}}{ }^{*}=\mathrm{S}$ value at the critical conditions

$\mathbf{S}\left(\theta^{*} ; \phi_{\mathrm{i}}\right)=$ normalized sensitivity of $\theta^{*}$ with respect to $\phi_{\mathrm{i}}$ $\left[\phi_{\mathrm{i}} / \theta^{*} \times \partial \theta^{*} / \partial \phi_{\mathrm{i}}\right]$

$\mathbf{S}\left(\theta_{\mathrm{s}}{ }^{*} ; \phi_{\mathrm{i}}\right)=$ normalized sensitivity of $\theta_{\mathrm{s}}{ }^{*}$ with respect to $\phi_{\mathrm{i}}$ $\left[\phi_{i} / \theta_{\mathrm{s}}^{*} \times \partial \theta_{\mathrm{s}}^{*} / \partial \phi_{\mathrm{i}}\right]$

$\mathbf{S}\left(\theta^{*} ; \theta_{\mathrm{w}}\right)=$ normalized sensitivity of $\theta^{*}$ with respect to $\theta_{\mathrm{w}}$ $\left[\theta_{\mathrm{w}} / \theta^{*} \times \partial \theta^{*} / \partial \theta_{\mathrm{w}}\right]$
$\mathbf{S}_{\mathrm{m}}\left(\theta^{*} ; \phi_{\mathrm{i}}\right)=$ maximum normalized objective sensitivity of

$\theta^{*}$ with respect to $\phi_{\mathrm{i}}$

$\mathrm{T}=$ absolute temperature, $\mathrm{K}$

$\mathrm{T}_{\mathrm{b}}=$ bulk temperature, $\mathrm{K}$

$\mathrm{T}_{\max }=$ maximum temperature, $\mathrm{K}$

$\mathrm{T}_{0}=$ feed temperature, $\mathrm{K}$

$\mathrm{T}_{\mathrm{w}}=$ wall temperature, $\mathrm{K}$

$\mathrm{U}=$ overall heat-transfer coefficient, $\mathrm{J} / \mathrm{m}^{2} \cdot \mathrm{s} \cdot \mathrm{K}$

$\mathrm{u}_{0}=$ superficial vel ocity, $\mathrm{m} / \mathrm{s}$

$\mathrm{v}_{0}=$ intraparticle fluid vel ocity, $\mathrm{m} / \mathrm{s}$

$\mathrm{X}_{\mathrm{F}}=$ formal dehyde conversion, $\left[\left(\mathrm{F}_{\mathrm{F}, 0}+\mathrm{X}_{\mathrm{M}} \mathrm{F}_{\mathrm{M}, 0}-\mathrm{F}_{\mathrm{F}}\right) /\left(\mathrm{F}_{\mathrm{F}, 0}\right.\right.$ $\left.\left.+\mathrm{X}_{M} \mathrm{~F}_{\mathrm{M}, 0}\right)\right]$

$X_{M}=$ methanol conversion, $\left[\left(F_{M, 0}-F_{M}\right) / F_{M, 0}\right]$

$\mathrm{Y}_{\mathrm{M}}=$ methanol molar fraction $\left[\mathrm{F}_{\mathrm{M}} / \Sigma \mathrm{F}_{\mathrm{i}}\right]$

$\mathrm{z}=$ reactor axial coordinate, $\mathrm{m}$

$\mathrm{z}^{*}=$ dimensionless reactor axial coordinate, $[\mathrm{z} / \mathrm{L}]$

Greek Symbols

$\alpha_{i, j}=$ stoichiometric coefficient of component $\mathrm{i}$, in reaction

j

$\Delta \mathrm{H}=$ reaction heat, $\mathrm{J} / \mathrm{mol}$

$\epsilon_{\mathrm{b}}=$ bed porosity

$\Phi=$ relative yield, $\left[\left(\mathrm{F}_{\mathrm{F}}-\mathrm{F}_{\mathrm{F}, 0}\right) /\left(\mathrm{F}_{\mathrm{M}, 0}-\mathrm{F}_{\mathrm{M}}\right)\right]$

$\Phi^{\prime}=$ differential yield of formaldehyde in respect to

methanol, [( $\left.\left.\mathrm{R}_{\mathrm{obs}, 1}-\mathrm{R}_{\mathrm{obs}, 2}\right) / \mathrm{R}_{\mathrm{obs}, 1}\right]$

$\phi_{\mathrm{i}}=$ model input parameter

$\phi_{\mathrm{i}, 0}=$ Thiele modulus at feed conditions, $\left[\mathrm{R}_{\mathrm{p}}\right.$ $\left.\sqrt{\rho_{\mathrm{p}} \mathrm{R}_{1,0} / \mathrm{D}_{\mathrm{e}, \mathrm{i}} \mathrm{C}_{\mathrm{M}, 0}}\right]$

$\gamma=$ Arrhenius number, $\left[\mathrm{E}^{\mathrm{a}} / \mathrm{RT}_{0}\right]$

$\eta_{\mathrm{j}}=$ effectiveness factor

$\lambda_{\mathrm{er}}=$ effective radial conductivity, $\mathrm{J} / \mathrm{m} \cdot \mathrm{s} \cdot \mathrm{K}$

$\lambda_{m, i}=$ mass intraparticle Peclet number, $\left[v_{0} R_{p} / D_{e, i}\right]$

$\theta=$ dimensionless temperature, $\left[\mathrm{T} / \mathrm{T}_{0}\right]$

$\theta_{\mathrm{b}}=$ dimensionless bulk temperature, $\left[\mathrm{T}_{\mathrm{b}} / \mathrm{T}_{0}\right]$

$\theta^{*}=$ dimensionless temperature at the hot spot conditions

$\left[\mathrm{T}_{\max } / \mathrm{T}_{0}\right]$

$\theta_{\mathrm{s}}{ }^{*}=$ dimensionless catalyst temperature at the hot spot,

$\left[\mathrm{T}_{\mathrm{s}, \max } / \mathrm{T}_{0}\right]$

$\theta_{\mathrm{w}}=$ dimensionless wall temperature, $\left[\mathrm{T}_{\mathrm{w}} / \mathrm{T}_{0}\right]$

$\rho=$ density, $\mathrm{kg} / \mathrm{m}^{3}$

Subscripts

$1,2=$ reaction 1 and 2

$\mathrm{b}=$ bulk conditions in the fluid phase

$d=$ diffusion

$\mathrm{dc}=$ diffusion and convection

$f=$ fluid

$\mathrm{F}=$ formaldehyde

$\mathrm{i}=$ component $\mathrm{i}$

$\mathrm{j}=$ reaction $\mathrm{j}$

$\mathrm{M}=$ methanol

$0=$ inlet conditions

$\mathrm{p}=$ particle

$\mathrm{s}=$ particle surface

$\mathrm{w}=$ wall

Superscripts

$*=$ hot spot conditions

$f=$ fluid

$\mathrm{p}=$ particle

$\mathrm{s}=$ particle surface

\section{Literature Cited}

(1) Bilous, O.; Amundson, N. R. Chemical Reactor Stability and Sensitivity. AIChE J . 1956, 2 (1), 117-126.

(2) Adler, J.; Enig, J. W. The Critical Conditions in Thermal Explosion Theory with Reactant Consumption. Combust. Flame 1964, 8, 97-103

(3) Dente, M.; Collina, A., II comportamento dei reattori chimici a flusso longitudinale nei riguardi della sensitività. Chim. Ind. 1964, 46 (7), 752-761. 
(4) van Welsenaere, R. J .; Froment, G. F. Parametric Sensitivity and Runaway in Fixed-Bed Catalytic Reactors. Chem. Eng. Sci. 1970, 25, 1503-1516.

(5) Morbidelli, M.: Varma, A. Parametric Sensitivity and Runaway in Tubular Reactors. AIChE J . 1982, 28 (5), 705-713.

(6) Morbidelli, M.; Varma, A. A Generalized Criterion for Parametric Sensitivity: Application to Thermal Explosion Theory. Chem. Eng. Sci. 1988, 43 (1), 91-102.

(7) Morbidelli, M.; Varma, A. Parametric Sensitivity in FixedBed Catalytic Reactors: The Role of Interparticle Transfer Resistances. AlChE J . 1986, 32 (2), 297-306.

(8) Morbidelli, M.; Varma, A. Parametric Sensitivity and Runaway in Fixed-Bed Catalytic Reactors. Chem. Eng. Sci. 1986 41 (4), 1063-1071.

(9) Morbidelli, M.; Varma, A. A Generalized Criterion for Parametric Sensitivity: Application to a Pseudohomogeneous Tubular Reactor with Consecutive or Parallel Reactions. Chem. Eng. Sci. 1989, 44 (8), 1675-1696.

(10) Puszynski, J.; Snita, D.; Hlavacek, V.; Hofmann, H. A Revision of Multiplicity and Parametric Sensitivity Concepts in Nonisothermal Nonadiabatic Packed Bed Chemical Reactors. Chem. Eng. Sci. 1981, 36 (10), 1605-1609.

(11) Rodrigues, A. E.; Quinta Ferreira, R. M. Effect of Intraparticle Convection on the Steady-State Behaviour of Fixed-Bed Reactors. Chem. Eng. Sci. 1990, 45, 2653-2660.

(12) Balakotaiah, V.; Kodra, D.; N guyen, D. Runaway Limits for Homogeneous and Catalytic Reactors. Chem. Eng. Sci. 1995, 50 (7), 1149-1171.

(13) Bauman, E.; Varma, A.; Lorusso, J .; Dente, M.; Morbidelli, M. Parametric Sensitivity in Tubular Reactors with Co-Current External Cooling. Chem. Eng. Sci. 1990, 45 (5), 1301-1307.

(14) J unco, G.; Brouwer, J. P.; Mulder, A. Sensitivity Analysis of the Methane Catalytic Combustion in a Sintered Metal Reactor with Integrated Heat Exchanger. Chem. Eng. Sci. 1996, 51 (11), $3101-3106$

(15) Strozzi, F.; Zaldívar, J. M. A General Method for Assessing the Thermal Stability of Batch Chemical Reactors by Sensitivity Calculation Based on Lyapunov Exponents. Chem. Eng. Sci. 1994 49 (16), 2681-2688.

(16) Vajda, S.; Rabitz, H. Parametric Sensitivity and SelfSimilarity in Thermal Explosion Theory. Chem. Eng. Sci. 1992, 47 (5), 1063-1078.

(17) Hlavàcek, V.; Marek, M.; J ohn, T. M. Modelling of Chemical Reactors. XII, Tubular Non-I sothermal Non-Adiabatic Packed Bed Reactors Analysis of a One-Dimensional Approximation. Collect. Czech. Chem. Commun. 1969, 34, 3868-3880

(18) Soria Lopez, A.; Lasa, H. I.; Porras, J. A. Parametric Sensitivity of a Fixed Bed Catalytic Reactor. Chem. Eng. Sci. 1981 36, 285-291.

(19) Morbidelli, M.; Varma, A. On Parametric Sensitivity and Runaway Criteria of Pseudohomogeneous Tubular Reactors. Chem. Eng. Sci. 1985, 40 (11), 2165-2168.

(20) Morbidelli, M.; Varma, A. Parametric Sensitivity in FixedBed Reactors: Inter- and Intraparticle Resistance. AIChE J . 1987, 33 (12), 1949-1958.

(21) Quinta Ferreira, R. Contribuição para o estudo de reactores catalíticos de leito fixo: efeito da convecção em catalisadores de poros largos e casos de catalisadores bidispersos. Ph.D. Thesis, Universidade do Porto, Porto, 1988.

(22) J unco, G.; Floarea, O. Sensitivity Analysis of Tubular Packed-Bed Reactor by Pseudohomogeneous 2-D Model. AIChE J. 1995, 41 (12), 2625-2630.

(23) El-Sawi, M.; Emig, G.; H offmann, U. Runaway of PackedBed Reactors. Int. Chem. Eng. 1978, 18 (2), 221-223.

(24) Emig, G.; Hofmann, H.; Hoffmann, U.; Fiand, U. Experimental Studies on Runaway of Catalytic Fixed-Bed Reactors (Vinyl-Acetate-Synthesis). Chem. Eng. Sci. 1980, 35, 249-257.
(25) Zaldívar, J . M.; Hernández, H.; Nieman, H.; Molga, E.; Bassani, C. The FIRES Project: Experimental Study of Thermal Runaway due to Agitation Problems during Toluene Nitration. J . Loss Prev. Process Ind. 1993, 6 (5), 319-326.

(26) Strozzi, F.; Alós, M. A.; Zaldívar, J. M. A Method for Assessing Thermal Stability of Batch Reactors by Sensitivity Calculation Based on Lyapunov Exponents: Experimental Verification. Chem. Eng. Sci. 1994, 49 (24B), 5549-5561.

(27) Heiszwolf, J . J .; Fortuin, J . M. H. Runaway Behaviour and Parametric Sensitivity of a Batch Reactor-An Experimental Study. Chem. Eng. Sci. 1996, 51 (11), 3095-3100.

(28) Westerterp, K. R.; Ptasinski, K.J . Safe Design of Cooled Tubular Reactors for Exothermic, Multiple Reactions. Parallel Reactions. Chem. Eng. Sci. 1984, 39 (2), 235-244.

(29) Westerterp, K. R.; Overtoom, R. R. Safe Design of Cooled Tubular Reactors for Exothermic, Multiple Reactions. Consecutive Reactions. Chem. Eng. Sci. 1985, 40 (1), 155-165.

(30) McGreavy, C.; Adderley, C. I. Generalized Criteria for Parametric Sensitivity and Temperature Runaway in Catalytic Reactors. Chem. Eng. Sci. 1973, 28, 577-584.

(31) Balakotaiah, V.; Luss, D. Explicit Runaway Criterion for Catalytic Reactors with Transport Limitations. AlChE J . 1991, 37 (12), 1780-1788.

(32) Baptista, C. M.; Castro, J . A. A Contribution to the Study of Runaway and Parametric Sensitivity in Fixed Bed Catalytic Reactors. Chem. Eng. Sci. 1996, 51 (11), 3119-3124.

(33) Dente, M.; Collina, A.; Pasquon, I. Verifica di un Reattore Tubolare per la Ossidazione del Metanolo a Formaldeide. Chim. Ind. 48 (6), 1966, 581-588.

(34) Dente, M.; Collina, A. Cinetica dell'ossidazione del metanol o a formaldeide con catalizzatore a base di ossidi di Fe e MoNota III. Chim. Ind. 1965, 47 (8), 821-829.

(35) Quina, M. J .; Quinta Ferreira, R. M. Model Comparison and Sensitivity Analysis for a Fixed Bed Reactor with Two Catalytic Zones. 1999, in press.

(36) Caracotsios, M.; Stewart, W. E. Sensitivity Analysis of Initial Value Problems with ODEs and Algebraic Equations. Comput. Chem. Eng. 1985, 9 (4), 359-365.

(37) Barkelew, C. H. Stability of Chemical Reactors. Chem. Eng. Prog. Symp. Ser. 1959, 55 (25), 37-46.

(38) Almeida-Costa, C. A.; Quinta Ferreira, R. M.; Rodrigues, A. E. Wrong-Way Behavior in Packed Bed Reactors with "LargePore" Catalysts. Chem. Eng. Sci. 1994, 49 (24B), 5571-5583.

(39) Rodrigues, A. E.; Quinta Ferreira, R. M. Convection, Diffusion and Reaction in a Large-Pore Catalyst Particle. AIChE Symp. Ser. 1988, 84, 80-87.

(40) Rodrigues, A. E.; Orfao, J .; Zoulalian, A. Intraparticle Convection, Diffusion and Zero Order Reaction in Porous Catalysts. Chem. Eng. Commun. 1984, 27, 327-337.

(41) Rodrigues, A. E.; Ahn, B. J .; Zoulalian, A. Intraparticle Forced Convection Effect in Catalyst Diffusivity Measurements and Reactor Design. AIChE J . 1982, 28 (4), 541-546.

(42) Nir, A.; Pismen, L. Simultaneous Intraparticle Forced Convection, Diffusion and Reaction in a Porous Catalyst-I. Chem. Eng. Sci. 1977, 32, 35-41.

(43) Quinta Ferreira, R. M.; Quina, M. M.J .; Rodrigues, A. E. Effect of Intraparticle Convection on the Critical Conditions of Operation of Fixed-Bed Reactors. In preparation, 1999.

Received for review November 18, 1998 Revised manuscript received J uly 12, 1999 Accepted September 8, 1999

IE 9807295 